\title{
Clinical Audit on the Provision of Diabetes Care in the Primary Care Setting by United Nations Relief and Works Agency for Palestine Refugees in the Near East (UNRWA)
}

\author{
Yousef Shahin ${ }^{1 *}$, Anil Kapur², Ali Khader1, Wafaa Zeidan'1, Anthony D. Harries ${ }^{3,4}$, \\ Jorn Nerup ${ }^{5}$, Akihiro Seita ${ }^{1}$ \\ ${ }^{1}$ United Nations Relief and Works Agency for Palestine Refugees in the Near East, UNRWA HQ (A), Amman, \\ Jordan \\ ${ }^{2}$ World Diabetes Foundation, Gentofte, Denmark \\ ${ }^{3}$ International Union Against Tuberculosis and Lung Disease (The Union), Paris, France \\ ${ }^{4}$ London School of Hygiene and Tropical Medicine, London, UK \\ ${ }^{5}$ Professor in Diabetes Care, Free Lancer, Denmark \\ Email: ${ }^{*} y$. shahin2@unrwa.org
}

Received 5 November 2014; revised 8 December 2014; accepted 17 December 2014

Academic Editor: Sharma S. Prabhakar, Texas Tech University Health Sciences Center, USA

Copyright $@ 2015$ by authors and Scientific Research Publishing Inc.

This work is licensed under the Creative Commons Attribution International License (CC BY).

http://creativecommons.org/licenses/by/4.0/

(c) (i)

Open Access

\section{Abstract}

OBJECTIVE: United Nations Relief and Works Agency for Palestine Refugees in the Near East (UNRWA) provides primary health care services including care for diabetes and hypertension, with limited resources under difficult circumstances in Gaza, West Bank, Jordan, Lebanon and Syria. A total of 114,911 people with diabetes were registered with UNRWA health centres in 2011. The aim of this cross-sectional observational study was to assess the quality of diabetes care in the UNRWA primary health care centres. METHOD: The study population consisted of 1600 people with diabetes attending the 32 largest UNRWA health centres and treated there for at least one year. Between April and Sept. 2012 data from medical records, including results of clinical examinations and laboratory tests performed during the last one year, current management including self-care education and evidence of diabetes complications were collected and recorded in a previously validated data collection form (DCF). Patients were interviewed and clinically examined on the day of the

\footnotetext{
Corresponding author.
}

How to cite this paper: Shahin, Y., Kapur, A., Khader, A., Zeidan, W., Harries, A.D., Nerup, J. and Seita, A. (2015) Clinical Audit on the Provision of Diabetes Care in the Primary Care Setting by United Nations Relief and Works Agency for Palestine Refugees in the Near East (UNRWA). Journal of Diabetes Mellitus, 5, 12-20. http://dx.doi.org/10.4236/jdm.2015.51002 
audit and blood collected for HbA1c testing which was done at a central lab using High-performance liquid chromatography (HPLC) method (HLC ${ }^{\circledR}-723$ G8 Tosoh Corporation, Japan). Data was transferred from paper records into a computer and analysed with Epi-info 2000. RESULTS: Type 1 diabetes was present in $4.3 \%$ and type 2 diabetes in $95.7 \%$. Co-morbid hypertension was present in $68.5 \%$; $90.3 \%$ were either obese $(64.0 \%)$ or overweight $(26.3 \%)$. Clinical management of diabetes was largely in line with UNRWA's technical instructions (TI) for diabetes. Records for 2 hour postprandial glucose ( $2 \mathrm{~h}$ PPG), serum cholesterol, serum creatinine, and urine protein analysis were available in $94.7 \%, 96.4 \%, 91.4 \%$ and $87.5 \%$, cases, respectively. Records of annual fundoscopic eye examination were available in $\mathbf{4 7 . 3 \%}$ cases but foot examinations were less well documented. Most patients (95.6\%) were on anti-diabetic drugs-68.2\% oral anti diabetic drugs (OAD) only, $14.4 \%$ combination of $\mathrm{OAD}$ and insulin, and $12.9 \%$ insulin only. While $44.8 \%$ patients had $2 \mathrm{~h}$ PPG $\leq 180 \mathrm{mg} / \mathrm{dl}$, only $28.2 \%$ had HbA1c $\leq 7 \% ; 55.5 \%$ and $28.2 \% \mathrm{had} \mathrm{BP} \leq 140 / 90$ and $\leq 130 / 80 \mathrm{~mm}$ of $\mathrm{Hg}$ respectively. Serum cholesterol $\geq 200 \mathrm{mg} / \mathrm{dl}$, serum creatinine $\geq 1.2 \mathrm{mg} / \mathrm{dl}$ and macro albuminuria were noted in $39.8 \%, 6.4 \%$ and $10.3 \%$ cases respectively. Peripheral neuropathy $(52.6 \%)$, foot infections $(17 \%)$, diabetic retinopathy $(11 \%)$ and myocardial infarction $(9.6 \%)$ were the most common long term complications. One or more episodes of hypoglycaemia were reported by $25 \%$ cases in total and in $48 \%$ of those using insulin. $17.7 \%$ and $22.6 \%$ cases received no or $\geq 4$ self-care education sessions respectively. CONCLUSION: The study confirmed that UNRWA doctors and nurses follow TI for diabetes and hypertension fairly well. Financial constraints and the consequent effects on UNRWA TI and policies related to diabetes care were important constraints. Key challenges identified were: reliance on $2 \mathrm{~h}$ PPG to measure control; non-availability of routine HbA1c testing, self-monitoring of blood glucose (SMBG) and statins within the UNRWA system; and high levels of obesity in the community. Addressing these will further strengthen UNRWA health system's efforts of providing services for diabetes and hypertension at the primary care level. Given that most developing countries either have no or only rudimentary services for diabetes and hypertension at the primary care level, UNRWA's efforts can serve as an inspiration to others.

\section{Keywords}

Diabetes Mellitus, Hypertension, Primary Care Setting, Palestine Refugees, Quality of Care, Clinical Audit, UNRWA

\section{Introduction}

UNRWA has worked in the Near East for 64 years, providing health, education and social services for over 5 million Palestine refugees in Jordan, Lebanon, Syria, the West Bank and Gaza Strip. Due to the prevailing socioeconomic conditions, psychological stress and lack of access to healthy food and physical activities, noncommunicable diseases (NCDs) such as, diabetes (DM), hypertension (HT), coronary artery disease (CAD) and cerebrovascular disease (CVD) are major problems for Palestine refugees The number of patients registered with DM has increased progressively and doubled in the last decade reaching 108,000 patients in 2012, without the data from Syria [1]. The exact prevalence of diabetes among Palestine refugees is not known, but may be assumed to be similar to the general population of the countries where they live, [2] i.e., 10.1\% in Jordan, 7.8\% in Lebanon, $8.6 \%$ in Palestine and $10.8 \%$ in Syria [3]; hence, likely to be between $8 \%$ and $11 \%$ among adults 20 - 79 years of age. Around $11.0 \%$ of people $\geq 40$ years attending UNRWA health facilities have DM [1].

UNRWA has provided care for DM and HT at their primary health care centres since 1992 and the NCD strategy has been revised four times with the latest revision in 2009 [4]. The current strategy is structured around three main elements-healthy life style promotion emphasizes the importance of weight control and regular exercise; early detection of diabetes by active screening of at risk individuals; and treatment protocols and effective case management with dietary management, physical exercise and risk assessment and screening for cardiovascular, cerebrovascular and peripheral vascular disease to prevent secondary complications. Another important element of the strategy is to improve record keeping, program effectiveness and quality of services. UNRWA has started to roll out an E-health initiative which allows periodic cohort monitoring and evaluation [5]-[8]. To 
improve care delivery, periodic assessment of knowledge, attitudes and practices of care providers using validated questionnaires and data collection tools supplemented with clinical audit is useful [9]-[14], the aim of this cross-sectional observational study was to assess the quality of diabetes care in the UNRWA primary care centres. In addition the study also assessed the UNRWA medical officers' ability to deliver DM care by evaluating their knowledge, attitude and practice regarding patients and services, which will be presented in another paper.

\section{Methods}

\subsection{Study Design}

Cross-sectional prospective survey of patients with DM.

\subsection{Setting}

The study was conducted in the 32 largest PHCs, with 8 each in the following locations Gaza, Jordan, Lebanon and the West Bank. Syria was not included due to the on-going armed conflict. In 2012, UNRWA had 116 PHC clinics in these four Fields serving a population of 3,134,732 refugees. Each clinic is staffed by 2 to 6 doctors and a variable number of nurses. All screening, diagnosis and treatment services at the clinic are provided freeof-charge.

Palestine refugees who attend the clinics are screened for DM if they are $\geq 40$ years old, at risk of non-communicable diseases, or pregnant or planning to get pregnant. Blood glucose tests are done by laboratory technicians and diagnosis is confirmed by medical officers if the fasting blood glucose (FBG) is $\geq 126 \mathrm{mg} / \mathrm{dl}$ on 2 separate occasions [4] [15]. If the readings are between $100-125 \mathrm{mg} / \mathrm{dl}$, a $75 \mathrm{~g}$ oral glucose tolerance test (OGTT) is performed to confirm or exclude diabetes. If FBG results are $\leq 100 \mathrm{mg} / \mathrm{dl}$ the patient is checked again in the following year. In the absence of facilities for testing for autoimmune markers for type 1 diabetes, children and young adults presenting with classical symptoms of diabetes - rapid loss of body weight with polyphagia, polyuria and polyhydria with or without ketonuria in the presence of random blood glucose $\geq 200 \mathrm{mg} / \mathrm{dl}$ or fasting glucose $\geq 126 \mathrm{mg} / \mathrm{dl}$ and requiring insulin treatment to control hyperglycemia are classified as type $1 \mathrm{DM}$. Persons diagnosed with DM are clinically assessed for co-morbidities and complications and these data along with demographic and clinical information are recorded in either patient registration files (hard copy) or in the E-Health system in health centres implementing electronic medical records. At registration, information on risk factors such as smoking, alcohol intake, physical activity and obesity (defined as body mass index $\geq 30 \mathrm{~kg} / \mathrm{m}^{2}$ ) are recorded.

Patients are managed according to a standard algorithm defined in the UNRWA TI, [4] with diet and lifestyle advice and different classes of anti-diabetic drugs that include OADs namely Glibenclamide, Gliclazide and Metformin and Insulin injections. Patients with uncontrolled DM are seen weekly, fortnightly or monthly until their $2 \mathrm{~h}$ PPG value is $\leq 180 \mathrm{mg} / \mathrm{dl}$ and subsequently followed every 3 months. Once a year all DM patients undergo blood tests for total serum cholesterol and creatinine, urine examination for macro-proteinuria and dilated fundoscopic eye examination During quarterly visits, weight, blood pressure (BP), PPG value, as well as presence of complications (defined as blindness, end-stage renal failure, myocardial infarction (MI), congestive cardiac failure, stroke, and above-ankle amputation) are recorded.

\subsection{Patient Population, Sampling Method and Size}

There were 114,911 DM patients receiving care in UNRWA health centres at the end of 2011 [16]. A sample size of 1600 patients (50 from each selected health centre namely 400 from each field) i.e., $14 \%$ of the total diabetes population in the UNRWA health system was considered sufficient to provide a representative sample. The first fifty consecutive patients visiting the selected clinic on assessment days with confirmed DM and receiving care at the same UNRWA NCD clinic for at least one year, were included in the study after they gave a written informed consent. Recruitment at the clinic was stopped on reaching the target of 50 patients.

\subsection{Source of Data, Variables, Reporting Formats and Analysis}

Patient data were obtained from paper and/or E-Health records and through direct interviews and recorded on the pre-tested DCF [9] [10] modified slightly to accommodate UNRWA TI and procedures. Variables included 
in the DCF were DM type, risk factors, weight/height/waist measurements, blood pressure, and prior year's medical records including documented lab tests, complications, information on self-monitoring, health education and current medication.

The DCF was completed in the patient's presence. To remove bias and ensure consistency across the study sites all patients were interviewed and clinically examined by staff responsible for NCD care at UNRWA Headquarters and field offices: Chief of Disease Prevention and Control and the Field Disease Control Officer, respectively. A local staff nurse or a trained NCD nurse assisted with the examination, and the local laboratory technician withdrew blood samples and facilitated the transportation for HbA1c testing at a non UNRWA central lab at the Augusta Victoria Hospital in East Jerusalem. HbA1c test was done using the High-performance liquid chromatography (HPLC) method (HLC ${ }^{\circledR}$-723G8 Tosoh Corporation, Japan). Data were transferred into a computer and analysed with Epi-info 2000.

\subsection{Ethics Approval}

Approval for the study was obtained from UNRWA Headquarters and the four Fields. Patients gave written consent for participation in the study.

\section{Results}

The characteristics of the 1600 patients included in the audit are shown in Table 1 . The mean age (SD) of the patients was 56.6 (12.6) years, ranging between 2 to 90 years. 37.5\% patients with type 2 diabetes were $<55$

\begin{tabular}{|c|c|c|c|}
\hline \multicolumn{2}{|c|}{ Mean Age Years $( \pm S D)$} & 1600 & $56.6( \pm 12.6)$ \\
\hline \multicolumn{2}{|c|}{ Mean Duration of DM Treatment Years $( \pm S D)$} & 1600 & $7.2 \pm 4.9$ \\
\hline \multicolumn{4}{|l|}{ Gender } \\
\hline & Female & 1020 & $63.8 \%$ \\
\hline & Male & 580 & $36.2 \%$ \\
\hline \multicolumn{4}{|l|}{ Type of DM } \\
\hline & Type 1 & 68 & $4.3 \%$ \\
\hline & Type 2 & 1532 & $95.7 \%$ \\
\hline \multicolumn{4}{|l|}{ BMI } \\
\hline & Underweight $(<18.5)$ & 18 & $1.1 \%$ \\
\hline & ormal weight (18.5 - 24.9) & 137 & $8.6 \%$ \\
\hline & Overweight (25 - 29.9) & 421 & $26.3 \%$ \\
\hline & Obese $(\geq 30)$ & 1024 & $64.0 \%$ \\
\hline \multicolumn{2}{|l|}{ Comorbid hypertension } & 1102 & $68.9 \%$ \\
\hline & $\mathrm{BP}>140 / 90 \mathrm{mmHg}$ & 490 & $44.5 \%$ \\
\hline & $\mathrm{BP}>130 / 80 \mathrm{mmHg}$ & 792 & $71.8 \%$ \\
\hline \multicolumn{2}{|l|}{$2 \mathrm{hr}$ PPG result available } & 1515 & $94.7 \%$ \\
\hline & 2 h PPG $\geq 180 \mathrm{mg} \%$ & 799 & $52.7 \%$ \\
\hline \multicolumn{2}{|l|}{ HbA1c tested during study } & 1600 & $100 \%$ \\
\hline & $\mathrm{HbA} 1 \mathrm{c} \geq 7.0 \%$ & 1148 & $71.8 \%$ \\
\hline \multicolumn{2}{|l|}{ S Cholesterol results available } & 1543 & $96.4 \%$ \\
\hline & S Cholesterol $\geq 200 \mathrm{mg} \%$ & 614 & $39.8 \%$ \\
\hline \multicolumn{2}{|l|}{ S Creatinine results available } & 1534 & $91.4 \%$ \\
\hline & S Creatinine $>1.2 \mathrm{mg} \%$ & 98 & $6.4 \%$ \\
\hline \multicolumn{2}{|l|}{ Proteinuria results available } & 1400 & $87.5 \%$ \\
\hline & Macro albuminuria + ve & 144 & $10.3 \%$ \\
\hline \multicolumn{2}{|l|}{ Fundoscopy results available } & 757 & $47.3 \%$ \\
\hline & Retinopathy + ve & 83 & $11.0 \%$ \\
\hline
\end{tabular}


years. Two thirds of the entire patients were female (63.8\%), which is in line with the gender distribution of patients attending UNRWA health centres (63.7\%). Duration of DM treatment was used as a surrogate marker for DM duration and it varied considerably, ranging from 1 - 30 years, with a mean (SD) duration of 7.2 (4.9) years. People with type 1 DM (8.1 (4.9) years and type 2 DM with hypertension 7.8 (5.0) years) had longer treatment duration compared to type 2 DM without hypertension (5.9 (4.3) years).

Type 1 DM was seen in 68 (4.2\%) cases, with a slight excess of females-37 to 31 males. Due to the selection criteria no case of gestational DM was included. Co-morbid hypertension was seen in 1102 (68.9\%), all of them with type 2 DM. This data is similar to that seen in the entire UNRWA health system DM cohort in 2011.

Being overweight or obese was common in the study population, the mean (SD) BMI was 32.1 (6.4). Overall 90.3\% were either overweight (26.3\%) or obese (64.0\%). Obesity was more common among women-73.1\% compared to $47.9 \%$ among men. Smoking was more prevalent among men (34.1\%) than women (11.3\%). Few patients gave history of alcohol consumption.

In terms of record keeping and monitoring, data on age, gender, BMI, type of DM, duration and type of DM treatment, frequency and topic of health education sessions, and information on self-monitoring were available in all 1600 cases. Records of $2 \mathrm{~h}$ PPG, fasting serum cholesterol, serum creatinine and urine protein values in the previous one year were available in $94.7 \%, 96.4 \%, 91.4 \%$ and $87.5 \%$ cases respectively.

The most common treatment was OAD; 68.2\% (1091) and 14.4\% (231) were receiving OADs alone or in combination with insulin respectively. Insulin alone was used in 12.9\% (207) cases and non-pharmacological lifestyle treatment (diet and exercise) alone in 3.9\% (63) cases. Eight cases while attending the UNRWA health system were receiving treatment from outside. Of the 1322 cases on OADs, 89.3\% (1181), 46.5\% (615) and 18\% (238) were receiving metformin, glibenclamide, and gliclazide alone or in combination respectively. Among subjects on insulin $72.5 \%$ were receiving $<60$ IU/day and $77.8 \%$ were self-injecting. SMBG was reported by $32.6 \%$ of all and $66.2 \%$ with type $1 \mathrm{DM}$.

The mean (SD) 2 h PPG value for 1515 cases where information was available was 200.2 (74.5) mg/dl, with the range from 65 to $632 \mathrm{mg} / \mathrm{dl}$. Table 2(a) and Table 2(b) show glycaemic control in relation to type of DM and type of treatment. In $44.4 \%$ cases the last recorded 2 h PPG was $\leq 180 \mathrm{mg} / \mathrm{dl}$. The proportion of cases with acceptable control was similar for different types of DM and was highest among those on non-pharmacological treatment (81\%), followed by those on OAD alone (47.9\%); OAD in combination with insulin (31.6\%) and insulin alone (30.9\%) —a reflection of disease duration and severity.

Table 2. (a) Glycaemic control in relation to type of DM; (b) Glycaemic control in relation to treatment.

(a)

\begin{tabular}{|c|c|c|c|c|c|c|c|}
\hline \multirow[t]{2}{*}{ DM Type } & \multicolumn{2}{|c|}{ Controlled } & \multicolumn{2}{|c|}{ Uncontrolled } & \multicolumn{2}{|c|}{ No Data } & \multirow[t]{2}{*}{ Total } \\
\hline & $\begin{array}{c}\text { 2-hr PPG } \\
(\leq 180 \mathrm{mg} / \mathrm{dl})\end{array}$ & $\begin{array}{l}\text { HbA1c } \\
(\leq 7.0 \%)\end{array}$ & $\begin{array}{c}\text { 2-hr PPG } \\
(>180 \mathrm{mg} / \mathrm{dl})\end{array}$ & $\begin{array}{l}\text { HbA1c } \\
(>7.0 \%)\end{array}$ & 2-hr PPG & HbA1c & \\
\hline Type 1 & 29 (42.6\%) & $5(7.4 \%)$ & 34 (50.0\%) & 63 (92.6\%) & $5(7.4 \%)$ & 0 & $68(100 \%)$ \\
\hline Type 2 & $183(42.6 \%)$ & $108(25.1 \%)$ & 226 (52.5\%) & 332 (74.9\%) & $21(4.9 \%)$ & 0 & $430(100 \%)$ \\
\hline DM with HTN & $504(45.7 \%)$ & 339 (30.8\%) & 539 (48.9\%) & 763 (69.2\%) & $59(5.4 \%)$ & 0 & $1102(100 \%)$ \\
\hline Total & $716(44.8 \%)$ & $452(28.3 \%)$ & 799 (49.9\%) & 1148 (71.7\%) & $85(5.3 \%)$ & $\mathbf{0}$ & $1600(100 \%)$ \\
\hline
\end{tabular}

(b)

\begin{tabular}{|c|c|c|c|c|c|c|c|}
\hline \multirow[t]{2}{*}{ Treatment } & \multicolumn{2}{|c|}{ Controlled } & \multicolumn{2}{|c|}{ Uncontrolled } & \multicolumn{2}{|c|}{ No Data } & \multirow[t]{2}{*}{ Total } \\
\hline & $\begin{array}{c}\text { 2-hr PPG } \\
(\leq 180 \mathrm{mg} / \mathrm{dl})\end{array}$ & $\begin{array}{l}\text { HbA1c } \\
(\leq 7.0 \%)\end{array}$ & $\begin{array}{c}\text { 2-hr PPG } \\
(>180 \mathrm{mg} / \mathrm{dl})\end{array}$ & $\begin{array}{l}\text { HbA1c } \\
(>7.0 \%)\end{array}$ & 2-hr PPG & HbA1c & \\
\hline Lifestyle & 51 (81.0\%) & 55 (87.3\%) & 4 (6.3\%) & 8 (12.7\%) & $8(12.7 \%)$ & 0 & 68 (100\%) \\
\hline OHA only & 523 (47.9\%) & 355 (32.5\%) & $516(47.3 \%)$ & 736 (67.5\%) & $52(4.8 \%)$ & 0 & $430(100 \%)$ \\
\hline OHA with insulin & 73 (31.6\%) & 19 (8.2\%) & 149 (64.5\%) & 212 (91.8\%) & 9 (3.9\%) & 0 & 1102 (100\%) \\
\hline Insulin only & 64 (30.9\%) & 18 (8.7\%) & 128 (61.8\%) & 189 (91.3\%) & $15(7.2 \%)$ & & \\
\hline Total & $711(44.4 \%)$ & 447 (27.9\%) & $797(49.8 \%)$ & $1145(71.2 \%)$ & $92(5.8 \%)^{*}$ & $8(0.5 \%)^{*}$ & $1600(100 \%)$ \\
\hline
\end{tabular}

*Type of treatment not known in 8 cases. 
The mean (SD) HbA1c was 8.3\% (1.9). Using an HbA1c with cut off value of 7.0\% as adequate control, only $27.9 \%$ cases were found to be under control, much lower than the $44.4 \%$ indicated by the last measured $2 \mathrm{~h}$ PPG value. When comparing results of HbA1c test with the last measured $2 \mathrm{~h}$ PPG values it was noted that while 86\% of subjects with $2 \mathrm{~h}$ PPG $\geq 180 \mathrm{mg} / \mathrm{dl}$ had $\mathrm{HbA1c}$ values $\geq 7 \%$, 56\% of subjects with $2 \mathrm{~h}$ PPG $\leq 180 \mathrm{mg} / \mathrm{dl}$ also had $\mathrm{HbAlc}$ values $\geq 7 \%$.

Results for serum cholesterol estimations were available in 96.4\% (1543) cases; the mean fasting value (SD) was 191.8 (49.1) mg\%. Hypercholesterolemia ( $\geq 200 \mathrm{mg} \%$ ) was seen in 39.8\% (614) cases. Results of serum creatinine test were available for $91.4 \%$ (1534) cases. The mean (SD) value was $0.865(0.44) \mathrm{mg} \%$. Elevated creatinine $(\geq 1.2 \mathrm{mg} \%)$ was seen in $6.4 \%$ of all cases, $4.9 \%$ of type 1 DM cases, and $3.7 \%$ of Type 2 DM cases without hypertension but was twice as frequent in cases with hypertension - 7.5\%. Urinary protein (macro albuminuria) estimation was done in $87.5 \%$ cases and was found raised in $10.3 \%$ cases.

Fundoscopy results were available for 757 cases (47.3\%). UNRWA ophthalmologists had examined 408 (53.9\%) and ophthalmologists from outside UNRWA had examined the remaining 349 (46.1\%). There were 83 (11\%) cases of retinopathy amongst those who had undergone fundoscopy.

The results of annual foot examination are shown in Table 3. Peripheral neuropathy was documented in $52.6 \%$ cases and was equally distributed among those with and without control based on the $2 \mathrm{~h}$ PPG results. Skin infections, both mycotic and bacterial, were documented in $17 \%$ cases.

There were 204 (12.8\%) patients in the study population with late complications, 186 had one and 18 had two complications. No case had more than two late complications. Details of late complications are shown in Table 4.

\section{Discussion}

The clinical audit of the UNRWA Non Communicable Disease (NCD) Care Programme, with a focus on diabetes care validated the general UNRWA approach to health service delivery and confirmed its capacity to manage diabetes care in a primary health care setting. At the same time, it conducted an in depth assessment of protocols, procedures and performance in NCD care, documenting in particular the strengths of UNRWA diabetes care and more importantly, highlighting some critical shortcomings that will help define priorities for further improvement.

The clinical audit confirmed that UNRWA medical providers working in diabetes care generally follow the TI

Table 3. Results of foot examination.

\begin{tabular}{cc}
\hline Foot condition & Number (\%) \\
\hline Peripheral neuropathy & $842(52.6 \%)$ \\
Fungal skin infection & $209(13.1 \%)$ \\
Bacterial skin infection & $63(3.9 \%)$ \\
Healed ulcer/gangrene & $30(1.9 \%)$ \\
Absence of foot pulse & $8(0.8 \%)$ \\
Above ankle amputation & $6(0.4 \%)$ \\
\hline
\end{tabular}

Table 4. Late diabetes complications.

\begin{tabular}{cc}
\hline Late complication & Number (\%) \\
Myocardial infarction & $149(9.3 \%)$ \\
Cerebral stroke & $34(2.1 \%)$ \\
Total blindness & $23(1.4 \%)$ \\
Amputation & $6(0.4 \%)$ \\
End stage renal disease & $6(0.4 \%)$ \\
\hline
\end{tabular}


rigorously. In terms of record keeping and monitoring, data on most parameters were available in over $90 \%$ cases including records of lab tests and clinical examinations performed in the last one year which is better than in similar studies done in other developing countries in tertiary care centres, albeit some years ago [10] [17].

Several shortcomings were identified some of which relate to financial constraints and the consequent effects on UNRWA TI and policy related to diabetes care. Only $45 \%$ of people with diabetes had $2 \mathrm{~h}$ PPG values within acceptable control $(\leq 180 \mathrm{mg} / \mathrm{dl})$ as defined by UNRWA TI. The control based on HbAlc testing $(\leq 7.0 \%)$ was even lower at $28 \%$, with the lowest control found in patients receiving insulin treatment $(7.4 \%)$ and this is a cause of concern. Relying on 2 h PPG done only during clinic visit could be misleading. Non availability of HbA1c tests to monitor control due to cost constraints means that UNRWA has systematically overestimated its quality of DM control.

Comorbid hypertension was present in 69\% (1102) cases and all of them were receiving antihypertensive medications. UNRWA TI defines blood pressure $\leq 140 / 90 \mathrm{~mm} \mathrm{Hg}$ as the control target even for people with diabetes with co morbid hypertension. This level is higher than currently recommended International Diabetes Federation (IDF) and American Diabetic Association (ADA) target of $\leq 130 / 80 \mathrm{~mm} \mathrm{Hg}$ for people with diabetes. Only 55.5\% of cases with co-existing hypertension had their last recorded BP $\leq 140 / 90 \mathrm{~mm} \mathrm{Hg}$ and only $28.2 \%$ had their BP $\leq 130 / 80 \mathrm{~mm} \mathrm{Hg}$. Hypertension control rates in this study are lower compared to the cumulative cohort data from six clinics in Jordan that use the E health record system where $87 \%$ of all patients had BP $\leq$ 140/90 mm Hg [7]. Uncontrolled hypertension in the setting of relatively poor glucose control is fertile ground for macro and microvascular complications particularly myocardial infarction, stroke, nephropathy and retinopathy. The fact that raised serum creatinine was seen twice as often in type 2 patients with co morbid hypertension and that $9.3 \%$ of cases had documented MI despite the relatively younger age, low prevalence of smoking and higher female gender mix in the study population points towards the need for more aggressive control of BP.

UNRWA TI defines the control target for total serum cholesterol at $<200 \mathrm{mg} / \mathrm{dl}$ or $<6.5 \mathrm{mmol} / \mathrm{L}$. Cholesterol levels were elevated in 39.8\% (614) cases. Because of financial constraints UNRWA cannot provide free treatment for hyperlipidaemia and as a consequence only half the patients (53.4\%) with raised cholesterol were on lipid lowering drugs, most of them paying out of pocket. Including free supply of lipid lowering drugs, in particular, a statin and paying greater attention to lifestyle counselling will be necessary to address the risk of cardiovascular disease.

Insufficient focus on lifestyle counselling was another shortcoming identified. More than $90 \%$ of people with DM within the UNRWA system are either obese (64.0\%) or overweight (26.3\%). Around $70 \%$ have co existing hypertension and almost $40 \%$ have hyperlipidaemia as noted above and all these conditions are amenable to prevention through lifestyle measures; requiring greater attention to lifestyle counselling. According to UNRWA TI, patients should receive at least four health education sessions during assessment visits each year. The audit revealed that $17.6 \%$ patients received no self-care education and only 361 (22.6\%) received four or more health education sessions, reflecting poor adherence to guidelines. Less than half the patients (40.6\%) recalled receiving relevant lifestyle health education sessions (exercise and diet). Although foot complication rates are significant (e.g. 53\% peripheral neuropathy and 13\% foot infections), only $16 \%$ of patients recalled receiving foot care advice. The same applies for counselling on hypoglycaemia, even though $20 \%-30 \%$ of patients were receiving insulin treatment. Better training, redefining roles and skilful deployment of non-medical health professionals may help improve self-care education and patient counselling.

The most prevalent early complication among patients was peripheral neuropathy seen in $52.6 \%$. History of MI or undergoing angioplasty was noted in $9.3 \%$ cases and is similar to the $9.7 \%$ prevalence of MI among diabetic patients from the region reported earlier [18]. The high rate of MI reflects the need to address underlying risk factors and to strictly follow UNRWA's secondary prevention strategy for people with DM and hypertension with stricter monitoring of BP and glycaemia control using HbA1c and introducing the use of statins.

The findings of this study are almost identical to those reported from tertiary care centres in other developing countries using a similar study protocol [10] [17] [19]-[22]. This indicates that in general people with type 2 DM have multiple comorbid conditions - overweight and obesity, hypertension, and dyslipidaemia. Control of hyperglycaemia, hypertension and hyperlipidaemia is less than satisfactory and complications are high. In many of these studies, the proportion of patients undergoing annual laboratory tests and examinations were much lower indicating poor adherence to protocols; level of control for glucose, blood pressure and lipids was lower and complication rates higher. 
The high prevalence of overweight or obesity and other risk factors in the study population points towards a need for a more comprehensive and strategic response that goes beyond the activities of the NCD care programme alone to address such fundamental issues and the recently applied Family Health Team reform [23] offers an ideal reference framework with focus on persons and families to address early prevention of disease by addressing family and community risk factors, early detection through systematic screening and provision of comprehensive care.

While more efforts are required to raise awareness and improve lifestyles through health promotion; the prevailing socioeconomic and psychological stress from the security situation in refugee camps poses a big challenge. Limited funding and need to prioritise scarce resources also places constraints on policy recommendations.

\section{Conclusion}

In conclusion, UNRWA's extensive experience in DM care in primary health care settings and the capacity, experience and rigour of their medical providers are a solid foundation on which to improve DM care. This study provides a basis to guide further actions aimed at modernizing and broadening DM care and address priorities for improvement by the UNRWA Health Department.

\section{Acknowledgements}

Special thanks to World Diabetes Foundation for financial and technical support to conduct the audit. We thank all UNRWA staff at the audited health centres and Field Control Officers for their cooperation in managing, follow up and monitoring patients.

\section{Conflicts of Interest}

None declared.

\section{Author Contributions}

Anil Kapur, Yousef Shahin and Akihiro Seita designed the study and wrote the first draft which was further developed by other authors. All authors contributed to the writing of the subsequent drafts and revisions of the paper, and all authors have read and approved the final paper for submission.

\section{References}

[1] United Nations Relief and Works Agency for Palestine Refugees in the Near East. UNRWA Health Department Annual Report 2012. Amman, Jordan: UNRWA, 2013.

[2] Husseini, A., Abu-Rmeileh, N.M., Mikki, N., Ramahi, T.M., Ghosh, H.A., Barghuthi, N., et al. (2009) Cardiovascular Diseases, Diabetes Mellitus, and Cancer in the Occupied Palestinian Territory. Lancet, 373, 1041-1049. http://dx.doi.org/10.1016/S0140-6736(09)60109-4

[3] Diabetes Atlas, International Diabetes Federation 2012. http://www.idf.org/diabetesatlas

[4] United Nations Relief and Works Agency Health Department. Technical Instructions and Management Protocols on Prevention and Control of Noncommunicable Diseases. Technical Instruction Series: HD/DC/01/1997. Revision No. 4. Amman, Jordan: UNRWA, 2009.

[5] Khader, A., Farajallah, L., Shahin, Y., Hababeh, M., Abu-Zayed, I., Kochi, A., et al. (2012) Cohort Monitoring of Persons with Diabetes Mellitus in a Primary Healthcare Clinic for Palestine Refugees in Jordan. Tropical Medicine International Health, 17, 1569-1576. http://dx.doi.org/10.1111/j.1365-3156.2012.03097.x

[6] Khader, A., Farajallah, L., Shahin, Y., Hababeh, M., Abu-Zayed, I., Kochi, A., et al. (2012) Cohort Monitoring of Persons with Hypertension: An Illustrated Example from a Primary Healthcare Clinic for Palestine Refugees in Jordan. Tropical Medicine International Health, 17, 1163-1170. http://dx.doi.org/10.1111/j.1365-3156.2012.03048.x

[7] Khader, A., Ballout, G., Shahin, Y., Hababeh, M., Farajallah, L., Zeidan, W., et al. (2013) Diabetes Mellitus and Treatment Outcomes in Palestine Refugees in UNRWA Primary Health Care Clinics in Jordan. Public Health Action, 3, 259-264. http://dx.doi.org/10.5588/pha.13.0083

[8] Khader, A., Ballout, G., Shahin, Y., Hababeh, M., Farajallah, L., Zeidan, W., et al. (2014) What Happens to Palestine Refugees with Diabetes Mellitus in a Primary Healthcare Centre in Jordan Who Fail to Attend a Quarterly Clinic Ap- 
pointment? Tropical Medicine International Health, 19, 308-312. http://dx.doi.org/10.1111/tmi.12256

[9] Jorgensen, L.N., Hajera, M., Pan, C.Y., Raheja, B.S., Sathe, S.A., Soweando, P., et al. (1999) DiabCare Asia Study. JAMA, 15, S40-41.

[10] Raheja, B.S., Kapur, A., Bhoraskar, A., Sathe, S.R., Jorgensen, L.N., Ram Moorthi, S., et al. (2001) Diabetes Care in India-Current Status. JAPI, 49, 717-722.

[11] Kapur, A., Shishoo, S., Ahuja, M.M.S., Sen, V. and Mankame, K. (1998) Diabetes Care in India: Physicians Perceptions, Attitudes and Practices. International Journal of Diabetes in Developing Countries, 18, 124-130.

[12] National Institute of Health and Clinical Excellence (2008) Audit Support-Type 2 Diabetes Clinical Criteria. NICE Clinical Guideline 66. http://www.ncbi.nlm.nih.gov/books/NBK11822/

[13] Shehab, A., Elnour, A. and Abdulle, A. (2012) A Clinical Audit on Diabetes Care in Patients with Type 2 Diabetes in Al-Ain, United Arab Emirates. The Open Cardiovascular Medicine Journal, 6, 126-132. http://dx.doi.org/10.2174/1874192401206010126

[14] Govender, I., Ehrlich, R., Van Vuuren, U., De Vries, E., Namane, M., De Sa, A., et al. (2012) Clinical Audit of Diabetes Management Can Improve the Quality of Care in a Resource-Limited Primary Care Setting. International Journal for Quality in Health Care, 24, 612-618. http://dx.doi.org/10.1093/intqhc/mzs063

[15] World Health Organization (2006) Definition and Diagnosis of Diabetes Mellitus and Intermediate Hyperglycaemia. Summary of Technical Report and Recommendations. WHO, Geneva.

[16] The United Nations Relief and Works Agency for Palestine Refugees in the Near East (2011) Annual Report Department of Health. http://www.unrwa.org/userfiles/file/publications/HealthReport2012.pdf

[17] Chuang, L.M., Tsai, S.T., Huang, B.Y. and Tai, T.Y. (2002) The Status of Diabetes Control in Asia-A Cross-Sectional Survey of 24317 Patients with Diabetes Mellitus in 1998. Diabetic Medicine, 19, 978-985. http://dx.doi.org/10.1046/j.1464-5491.2002.00833.x

[18] Al-Hazzaa, H.M. (2012) Prevalence and Risk Factors Associated with Nutrition-Related Non-Communicable Diseases in the Eastern Mediterranean Region. International Journal of General Medicine, 5, 199-217.

[19] Mafauzy, M., Hussein, Z. and Chan, S.P. (2011) The Status of Diabetes Control in Malaysia: Results of DiabCare 2008. Medical Journal of Malaysia, 66, 175-181.

[20] Soewondo, P., Soegondo, S., Suastika, K., Pranoto, A., Soeatmadji, D.W. and Tjokroprawiro, A. (2010) The DiabCare Asia 2008 Study_Outcomes on Control and Complications of Type 2 Diabetic Patients in Indonesia. Medical Journal of Indonesia, 19, 235-244. http://dx.doi.org/10.13181/mji.v19i4.412

[21] Chinenye, S., Uloko, A.E., Ogbera, A.O., Ofoegbu, E.N., Fasanmade, O.A., Fasanmade, A.A. and Ogbu, O.O. (2012) Profile of Nigerians with Diabetes Mellitus_Diabcare Nigeria Study Group (2008): Results of a Multicenter Study. Indian Journal of Endocrinology and Metabolism, 16, 558-564. http://dx.doi.org/10.4103/2230-8210.98011

[22] Sobngwie, E., Ndour-Mbayee, M., Boateng, K.F., Ramaiya, K.L., Njenga, E.W., Diop, S.N., Mbanya, J.C. and Ohwovoriole, A.E. (2012) Type 2 Diabetes Control and Complications in Specialised Diabetes Care Centres of Six Sub-Saharan African Countries: The Diabcare Africa Study. Diabetes Research and Clinical Practice, 95, 30-36. http://dx.doi.org/10.1016/j.diabres.2011.10.018

[23] Modern and Efficient UNRWA Health Services (2011) Family Health Team Approach. http://www.unrwa.org/sites/default/files/Health\%20Reform\%20Strategy.pdf 
Scientific Research Publishing (SCIRP) is one of the largest Open Access journal publishers. It is currently publishing more than 200 open access, online, peer-reviewed journals covering a wide range of academic disciplines. SCIRP serves the worldwide academic communities and contributes to the progress and application of science with its publication.

Other selected journals from SCIRP are listed as below. Submit your manuscript to us via either submit@scirp.org or Online Submission Portal.
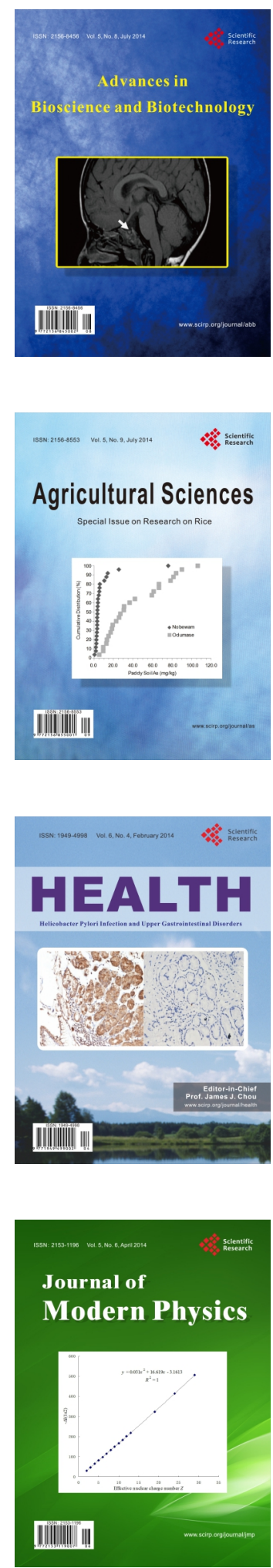
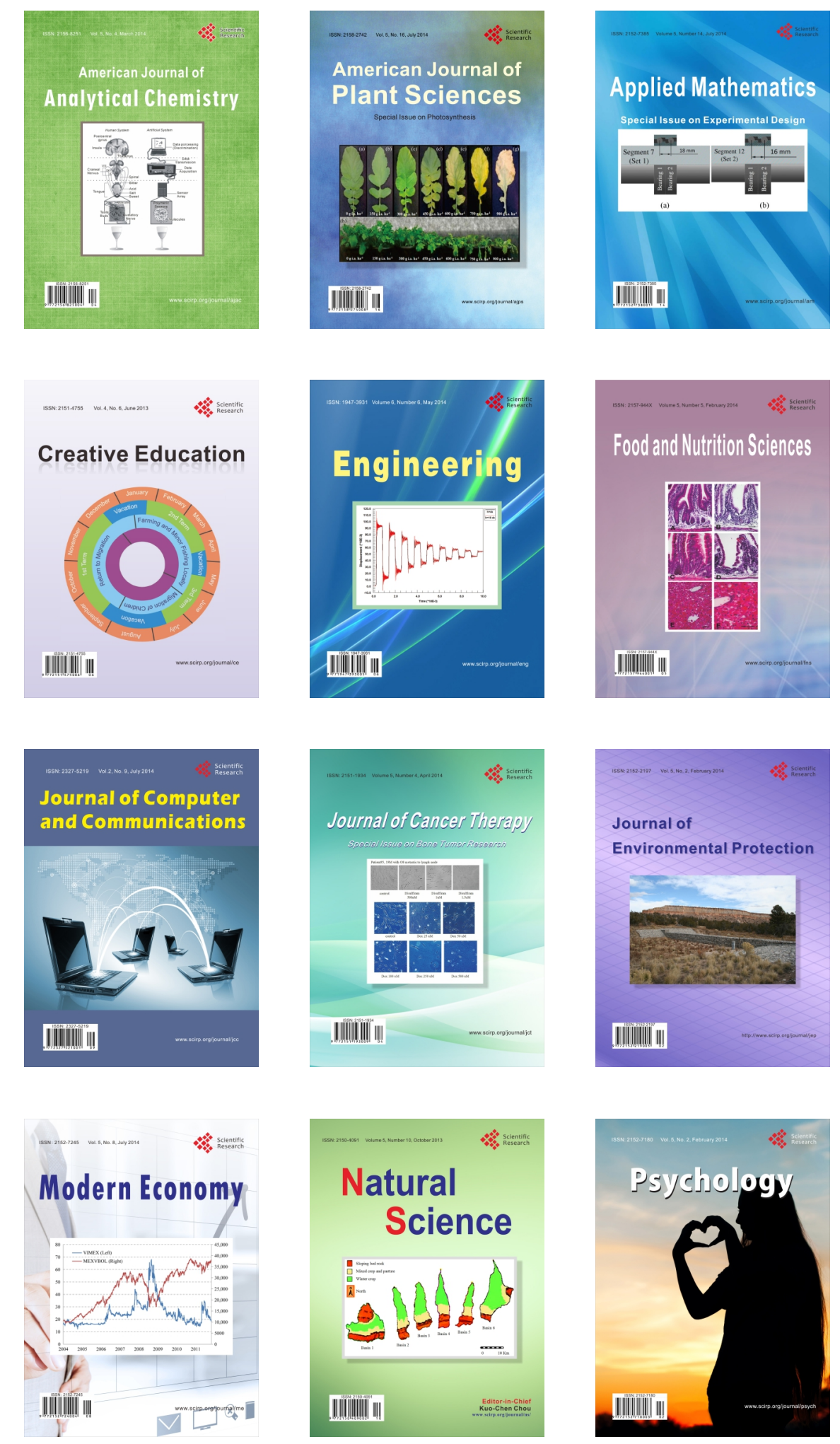